\title{
Successful resection of pancreatic metastasis from oesophageal squamous cell carcinoma: a case report and review of the literature
}

Wataru Koizumi ${ }^{1}$, Minoru Kitago ${ }^{1 *}$, Masahiro Shinoda ${ }^{1}$, Hiroshi Yagi ${ }^{1}$, Yuta Abe ${ }^{1}$, Go Oshima ${ }^{1}$, Shutaro Hori ${ }^{1}$, Kenta Inomata ${ }^{1}$, Hirofumi Kawakubo ${ }^{1}$, Miho Kawaida ${ }^{2}$ and Yuko Kitagawa ${ }^{1}$

\begin{abstract}
Background: Oesophageal cancer has a high metastatic potential and poor prognosis, with a significant risk of recurrence after radical resection. However, resected pancreatic metastasis from oesophageal cancer is rare.

Case presentation: Eleven years prior, a seventy-year-old woman had been treated with transthoracic radical oesophagectomy for oesophageal squamous cell carcinoma. Four years prior, she had undergone chemotherapy for lymph node recurrence at the splenic hilum and achieved a partial response. She had also received chemoradiotherapy for lymph node recurrence at the splenic hilum 3 years prior; a complete response was achieved. However, routine follow-up with abdominal computed tomography recently revealed a tumour at the pancreatic tail and swollen lymph nodes. The patient underwent distal pancreatectomy on the basis of a pre-operative diagnosis of primary pancreatic cancer, although a histological examination of the surgical specimen revealed metastatic squamous cell carcinoma that was compatible with metachronous pancreatic metastasis from oesophageal squamous cell carcinoma. The patient has been undergoing clinical follow-up without adjuvant therapy and has been disease-free for 24 months after resection of the pancreatic metastasis.
\end{abstract}

Conclusions: Resection of pancreatic metastasis may improve prognosis and should be considered when treating patients with solitary metastasis from oesophageal squamous cell carcinoma.

Keywords: Isolated metastasis, Pancreas, Pancreatic metastasis, Oesophageal cancer

\section{Background}

Oesophageal cancer has a high metastatic potential and poor prognosis, although recent advances in multimodal treatment using oesophagectomy and definitive chemoradiotherapy or chemotherapy have improved patient outcomes [1]. However, recurrence after radical oesophagectomy is detected in $30-50 \%$ of patients with haematogenous or lymphatic recurrence [2-4]. Pancreatic metastasis from oesophageal cancer is rare, with frequencies of $0.1,0.7$, and $2.9 \%$ for oesophageal cancer, metastatic oesophageal cancer, and oesophageal squamous cell

\footnotetext{
* Correspondence: dragonpegasus427@gmail.com; dragonpegasus@keio.jp ${ }^{1}$ Department of Surgery, Keio University School of Medicine, 35

Shinanomachi, Shinjuku-ku, Tokyo 160-8582, Japan

Full list of author information is available at the end of the article
}

carcinoma (OSCC), respectively [5]. Furthermore, less than $5 \%$ of cases of pancreatic metastases involve oesophageal cancer [6-8], and only few reports in the English literature have described the resection of pancreatic metastases from oesophageal cancer [9-11]. Here, we report a case of metachronous pancreatic metastasis from oesophageal cancer and provide a review of the literature.

\section{Case presentation}

Eleven years prior a seventy-year-old woman had undergone transthoracic radical oesophagectomy and cervical lymphadenectomy for OSCC (pathological T1bNOM0 stage I, according to the 7th edition of the Union for International Cancer Control/American Joint Committee on Cancer staging system). Seven years after surgery,

(c) The Author(s). 2019 Open Access This article is distributed under the terms of the Creative Commons Attribution 4.0 International License (http://creativecommons.org/licenses/by/4.0/), which permits unrestricted use, distribution, and 


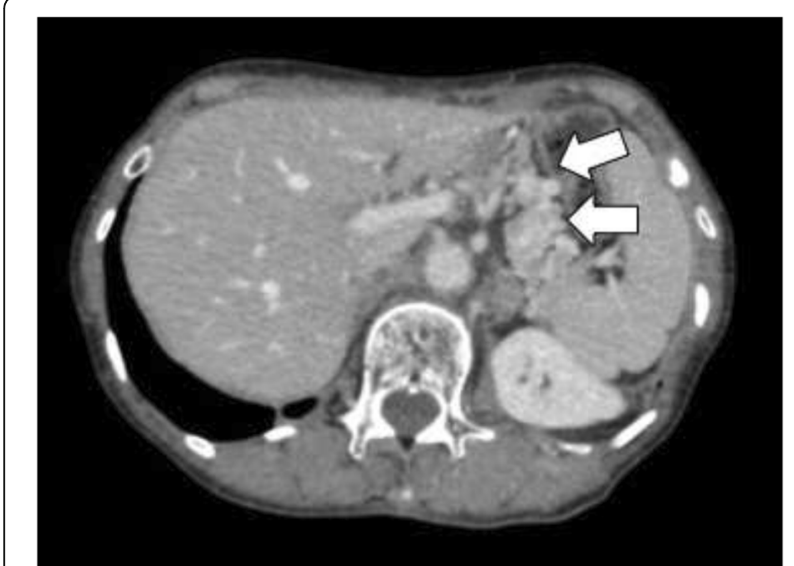

Fig. 1 Lymph node recurrence. Lymph node recurrence (white arrows) was detected at the splenic hilum 1 year after chemotherapy
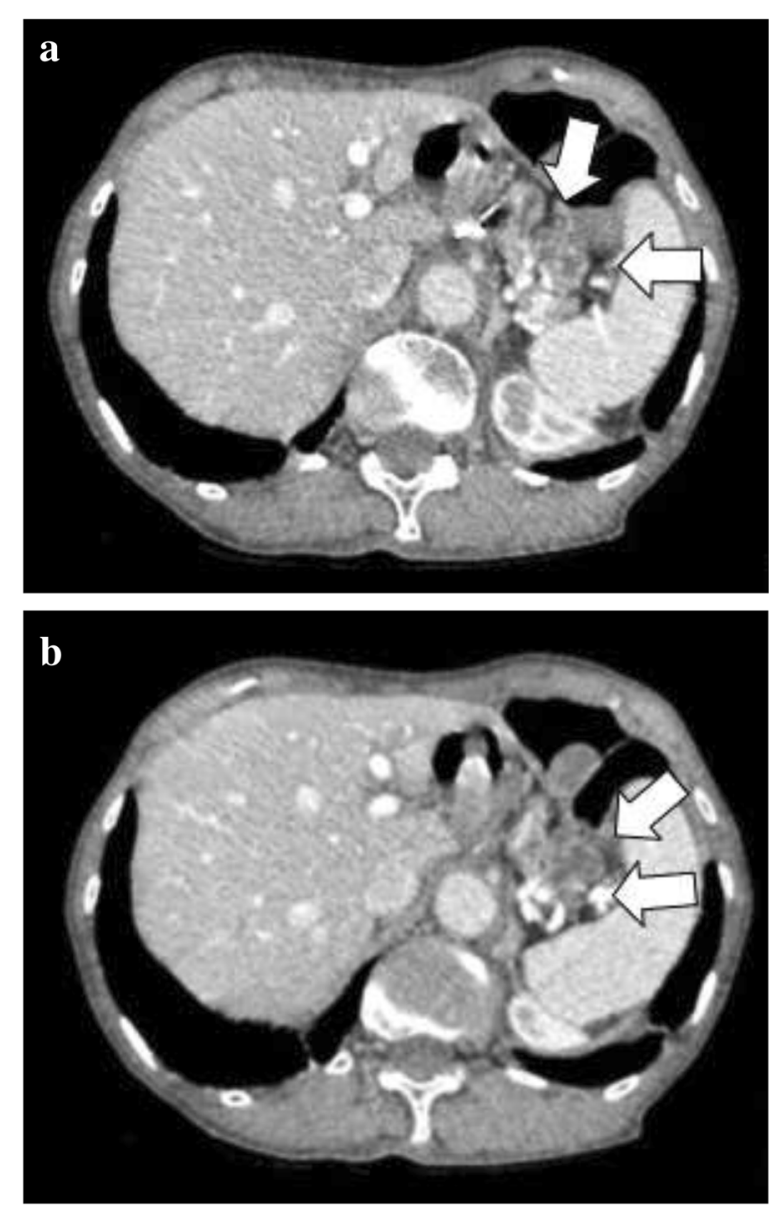

Fig. 2 Pre-operative computed tomography findings. Pre-operative computed tomography imaging detected $\mathbf{a}$ an adherent mass at the pancreatic tail and $\mathbf{b}$ a tumour above the mass
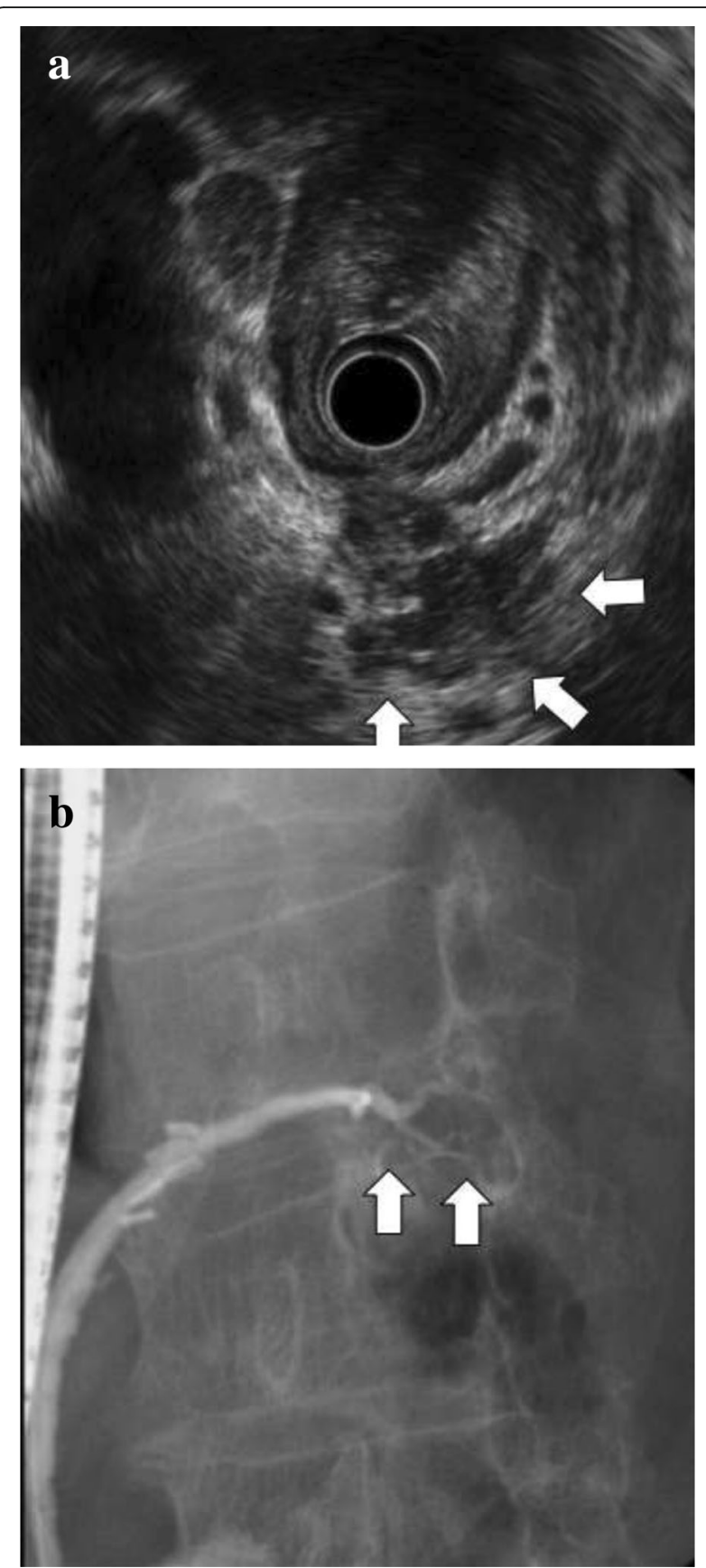

Fig. 3 a Pre-operative endoscopic ultrasonography/retrograde pancreatography findings. Pre-operative endoscopic ultrasonography detected an adherent mass at the pancreatic tail; $\mathbf{b}$ endoscopic retrograde pancreatography revealed narrowing of the main pancreatic duct in the pancreatic tail

computed tomography $(\mathrm{CT})$ revealed lymph node recurrence at the splenic hilum, which was treated with four courses of cisplatin plus 5-fluorouracil. Treatment reduced the size of the lymph node, although 1 year later, lymph node metastasis was detected again at the pancreatic tail and splenic hilum (Fig. 1). Chemoradiotherapy 


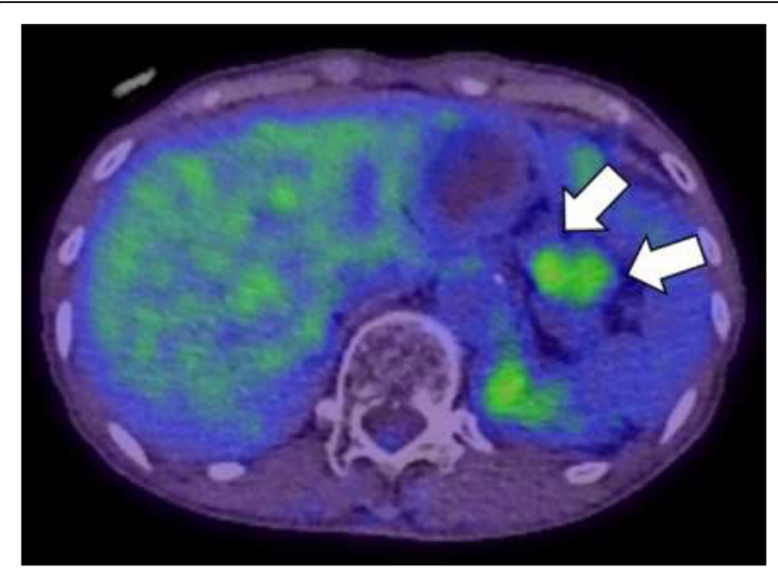

Fig. 4 Positron emission tomography/computed tomography findings. Positron emission tomography/computed tomography revealed a high standardised uptake value of 4.69 in the pancreatic tail mass (white arrows)

(50 Gy in 28 fractions) resulted in a complete response at the lymph nodes. However, 11 years after surgery, a cystic solid tumour was detected at the pancreatic tail using CT (Fig. 2a-b) and endoscopic ultrasonography (Fig. 3a). A change in the main pancreatic duct was also detected using endoscopic retrograde pancreatography (Fig. 3b). No other metastases were seen on evaluation with positron emission tomography/CT (Fig. 4), which strongly suggested primary pancreatic tail cancer with lymph node metastasis. Intraductal papillary mucinous carcinoma was one of the differential diagnoses that were considered. Distal pancreatectomy and splenectomy with lymphadenectomy were performed to treat the tumour, which had a diameter of $30 \mathrm{~mm}$ and appeared to invade the artery of the gastric tube that had been reconstructed during the oesophagectomy. Thus, the artery was also resected to achieve curative resection. Operative time was $190 \mathrm{~min}$ and blood loss was 30 $\mathrm{mL}$. The resected specimen from the pancreatic tail measured $29 \times 22 \times 30 \mathrm{~mm}$ (Fig. 5). Pathological examination revealed that the tumour was a squamous cell carcinoma, which was compatible with the detection of the previous OSCC. The final diagnosis was pancreatic metastasis from OSCC (Fig. 6). The resected metastatic lymph nodes at the splenic hilum also exhibited squamous cell carcinoma cells. The patient was discharged after an uneventful recovery. She is continuing clinical follow-up without adjuvant therapy and has been disease-free for 24 months after resection of the pancreatic metastasis.

\section{Discussion and conclusions}

Oesophageal cancer has a high metastatic potential and poor prognosis. Approximately a fifth of patients have

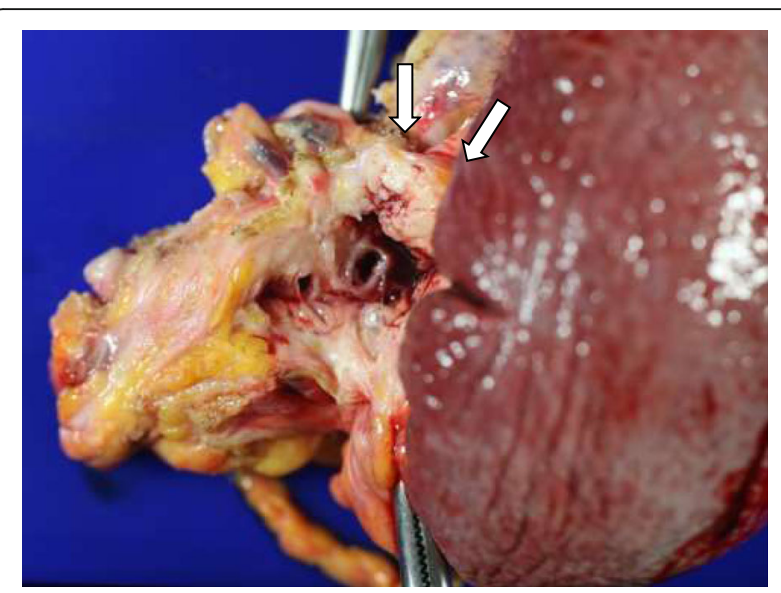

Fig. 5 Macroscopic examination. Macroscopic evaluation revealed a whitish tumour (measuring $29 \times 22 \times 30 \mathrm{~mm}$ ) in the pancreatic tail

distant metastasis at presentation. These distant metastases most commonly involve the abdominal lymph nodes (45.0\%), liver (35.0\%), lung (20.0\%), cervical or supraclavicular lymph nodes $(18.0 \%)$, bone $(9.0 \%)$, adrenal gland $(5.0 \%)$, peritoneum $(2.0 \%)$, or brain $(2.0 \%)$, as well as the stomach, pancreas, pericardium, and spleen (each 0.7\%) [5]. Autopsy studies revealed that the incidence of pancreatic metastasis ranged from 1.6 to $5.9 \%[6,12]$. In this context, pancreatic metastasis consists of a secondary pancreatic tumour or intrapancreatic metastasis [13], with the common sites of the primary tumour being the stomach, lung, extrahepatic bile duct, haematopoietic system, or gallbladder [12]. Pancreatic metastasis from oesophageal cancer is rare, with frequencies of $0.1,0.7$, and $2.9 \%$ for oesophageal cancer, metastatic oesophageal cancer, and OSCC, respectively

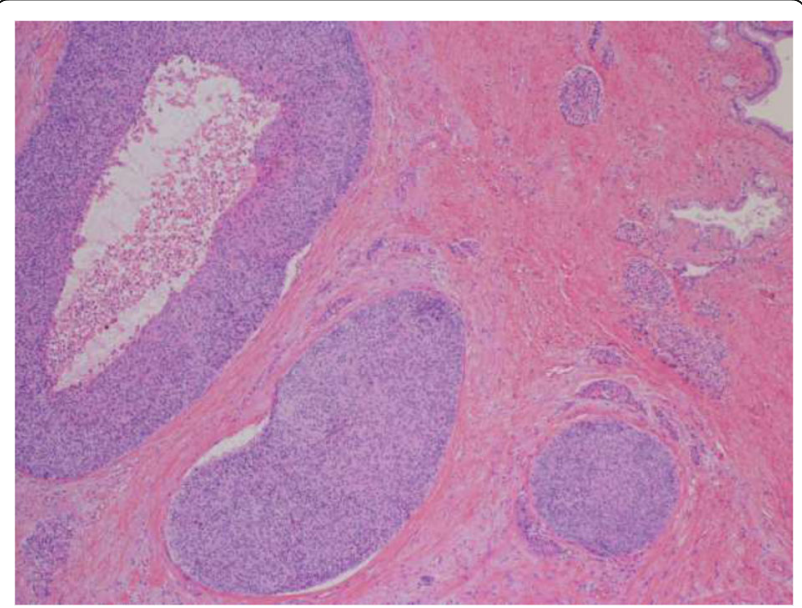

Fig. 6 Microscopic examination. Microscopic examination of squamous cells resembling oesophageal carcinoma resected 11 years prior showed that the pancreas exhibited a fibrous change in the background of the carcinoma 
Table 1 Reported cases of pancreatic metastasis from oesophageal carcinoma

\begin{tabular}{|c|c|c|c|c|c|c|c|c|}
\hline $\begin{array}{l}\text { Authors (year of } \\
\text { publication) }\end{array}$ & $\begin{array}{l}\text { Patient age } \\
\text { (years) }\end{array}$ & Sex & $\begin{array}{l}\text { Synchronous/ } \\
\text { metachronous }\end{array}$ & $\begin{array}{l}\text { Interval between } \\
\text { metastases (months) }\end{array}$ & Surgery & $\begin{array}{l}\text { Adjuvant } \\
\text { therapy }\end{array}$ & $\begin{array}{l}\text { Follow-up } \\
\text { (months) }\end{array}$ & Recurrence \\
\hline Esfehani et al. (2011) & 59 & $\mathrm{~F}$ & Metachronous & 48 & $\mathrm{DP}$ & $5-\mathrm{FU}$ & 4 & No \\
\hline Park et al. (2013) & 58 & M & Synchronous & 0 & $\mathrm{DP}$ & FP & 6 & No \\
\hline Okamoto et al. (2014) & 68 & M & Metachronous & 32 & $\mathrm{DP}$ & FP & 9 & No \\
\hline Present case & 81 & $\mathrm{~F}$ & Metachronous & 132 & DP & No & 24 & No \\
\hline
\end{tabular}

Abbreviations: 5-FU 5-fluorouracil, DP Distal pancreatectomy, F Female, FP 5-fluorouracil plus cisplatin, M Male

[5]; OSCC is only involved in $0-4.9 \%$ of cases of pancreatic metastases [6-8].

To the best of our knowledge, the English literature only contains 3 reports on the resection of isolated pancreatic metastases from OSCC (Table 1) [9-11]. Three cases, including the present case, were metachronously diagnosed during routine $\mathrm{CT}$ follow-up, whereas the remaining case was synchronously diagnosed during pre-operative examination for the treatment of primary oesophageal carcinoma. The interval between the diagnosis of the primary oesophageal cancer and the isolated pancreatic metastasis ranged from 0 to 132 months, with our case having the longest interval. In all cases, the pre-operative diagnosis was primary pancreatic carcinoma, and distal pancreatectomy was successfully performed with no surgical complications. A total of 3 reported cases involved planned adjuvant chemotherapy, and the patients were alive without recurrence 4-24 months after surgery.

It is important to determine whether pancreatic metastasectomy is an effective treatment option for cases of OSCC. Several reports have indicated that pancreatic metastasectomy provides a favourable prognosis $[7,13,14]$, although its effectiveness is dependent on the biology of the primary cancer and whether the metastasis is synchronous or metachronous. For example, long-term survival can be predicted on the basis of the cancer type such as renal cell carcinoma, colon cancer, or sarcoma [7]. Among patients with metachronous metastasis, a poor prognosis is associated with the presence of symptoms at diagnosis, synchronous metastases, and a disease-free interval of $<2$ years. Reddy et al. [7] reported that patients may benefit from pancreatic metastasectomy if they fulfil the following criteria: (1) primary cancer type that is associated with a favourable outcome, (2) control of the primary cancer, (3) isolated metastasis that can be resected, and (4) ability to tolerate pancreatectomy. Although the present case involved OSCC, the patient had metachronous disease with a long disease-free interval, unifocal metastasis, and response to systemic therapy, predicting a favourable outcome.

In conclusion, we describe a rare case of pancreatic metastasis from OSCC. On the basis of our findings and a review of the literature, we suggest that pancreatic metastasectomy may be a useful treatment option for isolated pancreatic metastasis from OSCC. However, accumulating evidence from additional cases is necessary to confirm our findings.

\section{Abbreviations}

CT: computed tomography; OSCC: oesophageal squamous cell carcinoma

\section{Acknowledgements}

We would like to thank Editage [www.editage.com] for English language editing.

Funding

No funding was received for this case report.

Availability of data and materials

All data generated or analysed during this study are included in this published article.

\section{Authors' contributions}

WK and MK analysed and interpreted the patient data based on the case notes. All authors have contributed to data collection and interpretation, and critically reviewed the manuscript. All authors read and approved the final manuscript.

Ethics approval and consent to participate

This study was approved by the ethics committee of the Keio University school of Medicine.

\section{Consent for publication}

Written informed consent was obtained from the patient for the publication of this case report and accompanying images.

\section{Competing interests}

The authors declare that they have no competing interests.

\section{Publisher's Note}

Springer Nature remains neutral with regard to jurisdictional claims in published maps and institutional affiliations.

\section{Author details}

${ }^{1}$ Department of Surgery, Keio University School of Medicine, 35 Shinanomachi, Shinjuku-ku, Tokyo 160-8582, Japan. ${ }^{2}$ Department of Pathology, Keio University School of Medicine, Tokyo, Japan.

Received: 15 September 2018 Accepted: 28 March 2019 Published online: 05 April 2019

\section{References}

1. Matsuda S, Takeuchi H, Kawakubo H, Ando N, Kitagawa Y. Current advancement in multidisciplinary treatment for resectable cStage I/II esophageal squamous cell carcinoma in Japan. Ann Thorac Cardiovasc Surg. 2016;22:275-83.

2. Nakagawa S, Kanda T, Kosugi S, Ohashi M, Suzuki T, Hatakeyama K. Recurrence pattern of squamous cell carcinoma of the thoracic esophagus 
after extended radical esophagectomy with three-field lymphadenectomy. J Am Coll Surg. 2004;198:205-11.

3. Takeuchi M, Takeuchi H, Kawakubo H, Booka E, Mayanagi S, Fukuda K, et al. Perioperative risk calculator predicts long-term oncologic outcome for patients with esophageal carcinoma. Ann Surg Oncol. 2018;25:837-43.

4. Shiozaki H, Sudo K, Xiao L, Wadhwa R, Elimova E, Hofstetter WL, et al. Distribution and timing of distant metastasis after local therapy in a large cohort of patients with esophageal and esophagogastric junction cancer. Oncology. 2014;86:336-9.

5. Quint L, Hepburn L, Francis I, Whyte R, Orringer M. Incidence and distribution of distant metastases from newly diagnosed esophageal carcinoma. Cancer. 1995;76:1120-5.

6. Adsay NV, Andea A, Basturk O, Kilinc N, Nassar H, Cheng J. Secondary tumors of the pancreas: an analysis of a surgical and autopsy database and review of the literature. Virchows Arch. 2004:444:527-35.

7. Reddy $S$, Wolfgang $C$. The role of surgery in the management of isolated metastases to the pancreas. Lancet Oncol. 2009:10:287-93.

8. Masetti M, Zanini N, Martuzzi F, Fabbri C, Mastrangelo L, Landolfo G, et al. Analysis of prognostic factors in metastatic tumors of the pancreas: a singlecenter experience and review of the literature. Pancreas. 2010;39:135-43.

9. Esfehani M, Mahmoodzadeh H, Alibakhshi A, Safavi F. Esophageal squamous cell carcinoma with pancreatic metastasis: a case report. Acta Med Iran. 2011:49:760-2

10. Park C, Jang JY, Kim YH, Hwang EJ, Na KY, Kim KY, et al. A case of esophageal squamous cell carcinoma with pancreatic metastasis. Clin Endosc. 2012:46:197-200

11. Okamoto H, Hara Y, Chin M, Hagiwara M, Onodera Y, Horii S, et al. An extremely rare case of pancreatic metastasis of esophageal squamous cell carcinoma. World J Gastroenterol. 2014;20:593-7.

12. Nakamura E, Shimizu M, Itoh T, Manabe T. Secondary tumors of the pancreas: clinicopathological study of 103 autopsy cases of Japanese patients. Pathol Int. 2001;51:686-90.

13. Fujita Y, Kitago M, Masugi Y, Itano O, Shinoda M, Abe Y, et al. Two cases of pancreatic ductal adenocarcinoma with intrapancreatic metastasis. World $J$ Gastroenterol. 2016;22:9222-8.

14. Varker K, Muscarella P, Wall K, Ellison C, Bloomston M. Pancreatectomy for non-pancreatic malignancies results in improved survival after Ro resection. World J Surg Oncol. 2007;5:145

Ready to submit your research? Choose BMC and benefit from:

- fast, convenient online submission

- thorough peer review by experienced researchers in your field

- rapid publication on acceptance

- support for research data, including large and complex data types

- gold Open Access which fosters wider collaboration and increased citations

- maximum visibility for your research: over $100 \mathrm{M}$ website views per year

At BMC, research is always in progress.

Learn more biomedcentral.com/submissions 